\title{
Prevalence and Risk Factors for Preeclampsia in Pregnant Women in Bulukumba District
}

\author{
Ely Kurniati ${ }^{1}$, Rusnawati ${ }^{2}$, Safruddin ${ }^{3 *}$, Risnawati ${ }^{4}$ \\ ${ }^{1,2,4}$ Department of Midwifery, Stikes Panrita Husada Bulukumba, Indonesia \\ ${ }^{, 3}$ Department of Nursing Stikes Panrita Husada Bulukumba, Indonesia
}

Corresponding author: Safruddin

Email: safaryahya1@gmail.com

\begin{abstract}
This study used a descriptive-analytic approach with the Historical Cohort Studies approach, to look at the mother's cohort book regarding the history of age, parity, BMI, and the living environment of mothers with pre-eclampsia in pregnant women in Bulukumba Regency. The stages in this study were collecting data on pregnant women who both experienced preeclampsia and those who were normal in each Public Health which consisted of 20 Public Health. Determining the sample with the sampling method cluster sampling which will then be drawn samples from each Puskesmas by simple random. Analyze the data that has been obtained using SPPS. The results of the study of 332 samples found that $259(78.1 \%)$ were normal and $73(21.9 \%)$ had preeclampsia. The results of the chi-square test showed that there were significant differences in proportions or other words age, body mass index (BMI). , parity and residential environment of pregnant women, influence the incidence of pre-eclampsia. The results of this study can be a source of data for future researchers and can provide input and recommendations for the Bulukumba Regency Government in making policies that are more targeted and focused on overcoming preeclampsia in pregnant women.
\end{abstract}

Keywords: Pre-Eclampsia, Pregnancy 


\section{PENDAHULUAN}

Kehamilan sangat erat kaitannya dengan persalinan, nifas dan bayi baru lahir. Kualitas pelayanan antenatal yang diberikan sangat mempengaruhi kesehatan ibu dan janinnya dalam proses persalinan, nifas maupun bayi baru lahir. Namun dalam perkembangannya, setiap kehamilan mempunyai risiko mengalami penyulit atau komplikasi. Oleh karena itu, untuk menjamin perlindungan terhadap ibu hamil dan janin maka dilakukan upaya deteksi dini faktor risiko komplikasi dalam kehamilan (Nurjasmi et al., 2016). Kematian ibu adalah kematian perempuan saat hamil atau kematian dalam kurun waktu 42 hari sejak terminasi kehamilan tanpa memandang lamanya kehamilan atau tempat persalinan, yakni kematian yang disebabkan karena kehamilannya atau pengelolaannya, tetapi bukan karena sebab-sebab lain seperti kecelakaan, terjatuh, dan lain-lain, atau banyaknya wanita yang meninggal dari suatu penyebab kematian tekait dengan gannguan kehamilan (rachmat latief, et al, 2015).

Data dari kementerian kesehatan republik indonesia tahun 2016 menerangkan bahwa Kematian ibu di Indonesia masih didominasi oleh tiga penyebab utama kematian yaitu perdarahan, hipertensi dalam kehamilan meliputi (preeklamsia-eklamsia) dan infeksi. Namun proporsinya telah berubah, dimana perdarahan dan infeksi cenderung mengalami penurunan sedangkan Hipertensi Dalam Kehamilan meliputi preeklamsia dan eklamsia proporsinya semakin meningkat. yaitu pada tahun 2010 telah terjadi kematian ibu (21,5\%), 2011 sebanyak (24,7\%), 2012 sebanyak (26,9\%) dan pada tahun 2013 meningkat menjadi (27,1\%). Dari data yang didapatkan dari dinas kesehatan Kabupaten Bulukumba, di tahun 2014 terdapat kematian ibu sebanyak 11 orang, 7 orang yang diakibatkan oleh preeklamsia $(63,63 \%)$, Tahun 2015 terdapat kematian sebanyak 7 orang, dengan kematian yang diakibatkan oleh eklamsia sebanyak 3 orang atau (42,85\%). Tahun 2016 terdapat kematian sebanyak 4 orang, dan tahun 2017 terdapat kematian sebanyak 7 orang, dengan kematian yang diakibatkan oleh hipertensi dalam kehamilan sebanyak 3 orang atau $(42,85 \%)$.

Preeklamsia merupakan komplikasi kehamilan yang ditandai dengan peningkatan tekanan darah disertai proteinuria pada wanita hamil yang sebelumnya tidak mengalami hipertensi. Biasanya sindroma ini muncul pada akhir trimester kedua sampai ketiga kehamilan. Gejalanya berkurang atau menghilang setelah melahirkan sehingga terapi defenitifnya mengakhiri kehamilan. Preeklamsia dapat berakibat buruk, bahkan menyebabkan kematian baik pada ibu maupun janin yang dikandungnya. Dampak akibat preeklamsia bisa berdampak pada ibu dan 
janin, tergantung pada derajat preeklamsia yang dialami. Namun yang termasuk komplikasi antara lain : dapat menyebabkan penderita mengalami Stroke, eklampsia, solusio plasenta, perdarahan subkapsula hepar, kelainan pembekuan darah (DIC), Sindrom HELLP, gagal jantung hingga syok dan kematian, Hipoksia janin, asfiksia neonatorum, premature, gagal ginjal, kebutaan, kejang, hipertensi permanen, distress fetal, infarkplasenta, abruption plasenta, kematian janin dalam uterus. Penelitian ini bertujuan untuk mengetahui Prevalensi dan Faktor Resiko Kejadian Preeklamsia pada Ibu Hamil di Kabupaten Bulukumba

\section{BAHAN DAN METODE}

\section{Desain Penelitian}

Penelitian ini menggunakan studi analitik dengan pendekatan Historical Cohort Studies, yakni melihat pada buku kohor ibu mengenai riwayat Umur, Paritas, IMT dan lingkungan tempat tinggal pada ibu yang mengalami Preeklamsia pada Ibu Hamil di Kabupaten Bulukumba.

\section{Populasi dan Sampel}

Adapun populasi dalam penelitian ini adalah seluruh data ibu hamil yang terdapat buku kohor Puskesmas Lingkup Dinas Kesehatan Kabupaten Bulukumba. Sampel pada penelitian ini adalah ibu hamil yang mengalami preeklamsia maupun yang normal yeng terdapat dalam buku kohor Puskesmas Lingkup Dinas Kesehatan Kabupaten Bulukumba periode tahun 2017. Dalam mengambil sampel penelitian ini digunakan metode pengambilan sampel menggunakan Cluster Sampling. Dimana jumlah ibu hamil sebanyak 332 orang

\section{Instrumen Penelitian}

Penelitian ini di lakukan dengan cara pengambilan data dari buku Kohort Puskesmas. Melihat buku kohort dan memberikan pengkodean secara manual pada kasus yang mengalami preeklamsia kemudian dicatat pada lembar yang telah disediakan.

\section{Tehnik Pengumpulan Data}

Dalam penelitian ini, data yang dikumpulkan adalah data sekunder yang diperoleh dari buku Kohort 20 Puskesmas yang terdapat di lingkup Dinas Kesehatan Kabupaten Bulukumba Periode 2017. 


\section{Analisis Data}

Data diuji menggunakan Uji bivariat menggunakan rumus uji Chi Square, jika data berdistribusi normal dan jika nilai probabilitas signifikasi >0,05 maka tidak terdapat perbedaan yang signifikan, sebaliknya jika nilai probabilitas signifikasi.

\section{HASIL}

Hasil penelitian yang telah dilakukan jumlah ibu bersalin di Puskesmas Se-Kabupaten Bulukmba sebanyak 3.142 orang.Denganjumlahrespondensebanyak 332 Orang di 20 Puskesmas Se-Kabupaten Bulukumba. Table 1 menunjukkan bahwa Responden pada kelompok umur berisiko 119 orang $(35.8 \%)$ lebih rendah dibandingkan dengan kelompok umur yang tidak beresiko 213 (64.2), responden dengan paritas terbanyak pada kelompok multipara dengan 197 orang (59.3\%). Responden status gizi terbanyak normal dengan 185 orang $(55.7 \%)$. Responden pada lingkungan terbanyak 249 orang (75 \%) dan proporsi responden yang menagalami pre eklamsia sebanyak 72 orang (22\%) di Kabupaten Bulukumba.

Tabel 1. Distribusi Frekuensi Kelompokumur, Paritas, Status Gizi Ibu Bersalin

\begin{tabular}{lcc}
\hline \multicolumn{1}{c}{ Variabel } & Frekuensi & Persentase (\%) \\
\hline Kelompok Umur & & \\
$\quad$ Berisiko & 119 & 35.8 \\
$\quad$ Tidak & 213 & 64.2 \\
Paritas & & \\
$\quad$ Primipara & 121 & 36.4 \\
Multipara & 197 & 59.3 \\
Grande & 14 & 4.2 \\
Status Gizi & & 2.7 \\
Kurang & 9 & 55.7 \\
Normal & 185 & 41.6 \\
Lebih & 138 & 75 \\
Lingkungan & & 25 \\
Pesisir + dataranrendah & 249 & \\
Perbukitan + datarantinggi & 83 & 22 \\
Pre Eklamsia & 73 & 78 \\
Terjadi & 259 & \\
Tidak & & $\mathbf{1 0 0 , 0}$ \\
\hline
\end{tabular}

Berdasarkan tabel 2 menunjukkan bahwa Responden yang memiliki umurberisiko lebih besar mengalami Preeklampsia 47 orang (39.5\%) dibandingkan dengan umur yang 
tidakberisiko 26 orang (12.2\%) Sehingga secara presentase (Proporsi) dapat disimpulkan bahwa ada perbedaan kejadian pre eklamsia berdasarkan umur. Hasil Uji statistik Chi-Square menunjukkan bahwa nilai $p=0,000(p<0,05)$ hal ini menunjukkan ada perbedaan proporsi secara bermakna kejadian Preeklampsia antara umur yang berisiko dan tidak. Atau dengan kata lain kelompok umur mempengaruhi kejadian pre eklamsia.

Tabel 2. Analisis Hubungan kelompokumur dengan kejadian Preeklampsia pada Ibu Bersalin Di Kabupaten Bulukumba

\begin{tabular}{lccccccc}
\hline & \multicolumn{4}{c}{ Kejadian Preeklampsia } & \multicolumn{2}{c}{ Jumlah } & \multirow{2}{*}{ Umur } \\
\cline { 2 - 5 } \multicolumn{1}{c}{ Uneeklampsia } & \multicolumn{2}{c}{ Tidak Preeklampsia } & & & $\boldsymbol{P}$ \\
\cline { 2 - 6 } & $\mathrm{f}$ & $\%$ & $\mathrm{f}$ & $\%$ & $\mathrm{f}$ & $\%$ & \\
\hline Berisiko & 47 & 39.5 & 72 & 60.5 & 119 & 100 & 0,000 \\
Tidak & 26 & 12.2 & 187 & 87.8 & 213 & 100 & \\
\hline Jumlah (n) & $\mathbf{7 3}$ & $\mathbf{2 2 , 0}$ & $\mathbf{2 5 9}$ & $\mathbf{7 8 , 0}$ & $\mathbf{3 3 2}$ & $\mathbf{1 0 0}$ & \\
\hline
\end{tabular}

Berdasarkan tabel 3 menunjukkan bahwa Responden yang memiliki Indeks Massa Tubuh Lebih 50 orang $(36,2 \%)$ lebih besar mengalami Preeklampsia dibandingkan dengan Responden yang memiliki Indeks Massa Tubuh Normal 22 orang (11,9\%) dan Indeks Massa Tubuh Kurang 1 orang $(11,1 \%)$. Sehingga secara presentase (Proporsi) dapat disimpulkan bahwa Ada Kecenderungan yang mengalami Preeklampsia yang memiliki Indeks Massa Tubuh Lebih. Hasil Uji statistik Chi-Square menunjukkan bahwa nilai $P=0,000(P<0,05)$ hal ini terbukti bahwa Indeks Massa Tubuh Lebih berhubungan secara bermakna dengan kejadian Preeklampsia.

Tabel 3. Analisis Hubungan Indeks Massa Tubuh dengan kejadian Preeklampsia pada Ibu Bersalin Di Kabupaten Bulukumba

\begin{tabular}{|c|c|c|c|c|c|c|c|}
\hline \multirow[t]{3}{*}{ IMT } & \multicolumn{4}{|c|}{ Kejadian Preeklampsia } & \multirow{2}{*}{\multicolumn{2}{|c|}{ Jumlah }} & \multirow{3}{*}{$\boldsymbol{P}$} \\
\hline & \multicolumn{2}{|c|}{ Preeklampsia } & \multicolumn{2}{|c|}{ Tidak Preeklampsia } & & & \\
\hline & $\mathrm{F}$ & $\%$ & $\mathrm{f}$ & $\%$ & $\mathrm{f}$ & $\%$ & \\
\hline Kurang & 1 & 11,1 & 8 & 88,9 & 9 & 100,0 & \\
\hline Normal & 22 & 11,9 & 163 & 88,1 & 185 & 100,0 & 0,000 \\
\hline Lebih & 50 & 36,2 & 88 & 63,8 & 138 & 100,0 & \\
\hline Jumlah (n) & 73 & 22,0 & 259 & $\mathbf{7 8 , 0}$ & 332 & 100,0 & \\
\hline
\end{tabular}

Table 4 menunjukkan bahwa Responden yang memiliki paritasprimi30 orang $(24,8 \%)$ lebih besar proporsinyamengalami Preeklampsia dibandingkan dengan Responden yang memiliki paritas multidengan 37 orang (18.8\%) dan proporsi terbesar pada grande dengan 6 orang (42.9\%). Sehingga secara presentase (Proporsi) dapat disimpulkan bahwa Ada Kecenderungan yang mengalami Preeklampsia yang mengalami pre eklamsia pada grande. 
Hasil Uji statistik Chi-Squaremenunjukkan bahwa nilai $P=0,071(P>0,05)$ hal ini menunjukkan bahwa tidak ada perbedaan proporsi kejadian pre eklamsia berdasarkan gravid.

Tabel 4.Analisis Hubungan paritas dengan kejadian Preeklampsia pada Ibu Bersalin Di Kabupaten Bulukumba

\begin{tabular}{|c|c|c|c|c|c|c|c|}
\hline \multirow{3}{*}{ Paritas } & \multicolumn{4}{|c|}{ Kejadian Preeklampsia } & \multirow{2}{*}{\multicolumn{2}{|c|}{ Jumlah }} & \multirow{3}{*}{$\boldsymbol{P}$} \\
\hline & \multicolumn{2}{|c|}{ Preeklampsia } & \multicolumn{2}{|c|}{$\begin{array}{l}\text { Tidak } \\
\text { Preeklampsia }\end{array}$} & & & \\
\hline & $\mathbf{F}$ & $\%$ & $\mathbf{f}$ & $\%$ & $\mathbf{f}$ & $\%$ & \\
\hline Primi & 30 & 24.8 & 91 & 75.2 & 121 & 100,0 & \\
\hline Multi & 37 & 18.8 & 160 & 81.2 & 197 & 100,0 & 0,071 \\
\hline grande & 6 & 42.9 & 8 & 57.1 & 14 & 100,0 & \\
\hline Jumlah (n) & 73 & 22,0 & 259 & 78,0 & 332 & 100,0 & \\
\hline
\end{tabular}

dataranrendah lebih besar mengalami Preeklampsia 60 orang $(24.1 \%)$ dibandingkan dengan responden yang bertempat tinggal di daerah perbukitan + dataran tinggi13 orang (15.7\%) Sehingga secara presentase (Proporsi) dapat disimpulkan bahwa ada perbedaan kejadian pre eklamsia berdasarkan lingkungan. Hasil Uji statistik Chi-Square menunjukkan bahwa nilai $p$ $=0,108(p>0,05)$ hal ini menunjukkan secara statistic tidak ada perbedaan proporsi secara bermakna kejadian Pre eklampsia antara responden yang tinggal di daerah pesisir dan daerah perbukitan

Tabel 5. Analisis Hubungan lingkungan dengan kejadian Preeklampsia pada Ibu Bersalin Di Kabupaten Bulukumba

\begin{tabular}{lcccccccc}
\hline & \multicolumn{4}{c}{ Kejadian Preeklampsia } & \multicolumn{2}{c}{ Jumlah } & \multirow{2}{*}{$\boldsymbol{P}$} \\
\cline { 2 - 6 } \multicolumn{1}{c}{ Lingkungan } & \multicolumn{2}{c}{ Preeklampsia } & \multicolumn{2}{c}{ Tidak Preeklampsia } & & \\
\cline { 2 - 7 } \multicolumn{1}{c}{} & $\mathrm{f}$ & $\%$ & $\mathrm{f}$ & $\%$ & $\mathrm{f}$ & $\%$ & \\
\hline Pesisir & 60 & 24.1 & 189 & 75.9 & 249 & 100 & 0,108 \\
Perbukitan & 13 & 15.7 & 70 & 84.3 & 83 & 100 & \\
\hline Jumlah (n) & $\mathbf{7 3}$ & $\mathbf{2 2 , 0}$ & $\mathbf{2 5 9}$ & $\mathbf{7 8 , 0}$ & $\mathbf{3 3 2}$ & $\mathbf{1 0 0}$ & \\
\hline
\end{tabular}

Tabel 6 menunjukkan bahwa hasil uji regresi logistik, variabel yang paling berpengaruh terhadap kejadian pre eklamsia pada ibu bersalin tahun 2017 adalah kelompok umur dengan nilai (B : 1.689, Exp B 5.414). 
Tabel 6. Ringkasan Analisis Multivariat Analisis factor - factor yang berhubungan dengan kejadian Preeklampsia pada Ibu Bersalin Di Kabupaten Bulukumba

\begin{tabular}{|c|c|c|c|c|c|c|c|}
\hline \multicolumn{8}{|c|}{ Variables in the Equation } \\
\hline & & $\bar{B}$ & S.E. & Wald & df & Sig. & $\overline{\operatorname{Exp}(B)}$ \\
\hline \multirow{5}{*}{ Step $1^{\mathrm{a}}$} & Klp Umur & 1.689 & .306 & 30.490 & 1 & .000 & 5.414 \\
\hline & Kode & -1.598 & .307 & 27.055 & 1 & .000 & .202 \\
\hline & Gravid & .018 & .256 & .005 & 1 & .945 & 1.018 \\
\hline & Lingkungan & .922 & .385 & 5.751 & 1 & .016 & 2.515 \\
\hline & Constant & 1.497 & .983 & 2.318 & 1 & .128 & 4.470 \\
\hline
\end{tabular}

\section{PEMBAHASAN}

Hasil penelitian menunjukkan bahwa Kejadian preeclampsia disebabkan oleh banyak factor seperti umur, paritas dan lingkungan. Pada factor umur sering terjadi pada usia muda <20 tahun karena alat reproduksinya belum sempurna sehingga rentang mengalami preeclampsia dan pada usia tua>35 tahun karena pada usia tersebut selain terjadi kelemahan fisik dan terjadi perubahan, penurunan pada jaringan dan alat kandung serta jalan lahir tidak lentur lagi, pada usia tersebut cenderung didapatkan penyakit lain dalam tubuh ibu salah satunya hipertensi, hal ini dikarenakan tekanan darah tinggi yang meningkat seiring dengan penambahan usia sehingga dapat memungkinkan terjadinya preeclampsia. Penelitian ini sesuai dengan penelitian Evi Herawati (2017), yang meneliti tentang hubungan usia dengan kejadian preeclampsia pada ibu bersalin di RSUD Muntilan. Hasil analisis bivariat menunjukkan adanya hubungan signifikan antara kejadian preeclampsia dengan responden usia berisiko ( $<20$ tahun dan $>35$ tahun).

Pada umumnya primigravida adalah salah satu faktor penyebab terjadinya preeklamsia. berbagai faktor yaitu primigravida, riwayat keluarga dengan preeklamsia, kehamilan kembar, kondisi medis tertentu, adanya proteinuria, umur $>35$ tahun, hipertensi kronik yang sudah diderita sebelum hamil (preeklamsia superimposed) dan obesitas. Penelitian ini memiliki keterkaitan dengan penelitian yang dilakukan oleh Anita Safitri (2016), Hubungan Graviditas dengan kejadian preeklamsia di Rumah Sakit Umum Dewi Sartika Kendari Provinsi Sulawesi 
Tenggara dan diperkuat oleh Sri Sumarni (2014), Risnawati, R. and Kurniati, E. (2018) bahwa ada hubungan graviditas ibu dengan kejadian preeklamsia.

Kejadian Preeklampsia juga disebabkan berat badan yang berlebih atau obesitas. Pengenalan penyakit dan pemeriksaan antenatal memegang peran penting di dalam menghindari komplikasi yang dapat terjadi baik selama kehamilan maupun dalam persalinan. Hasil ini sejalan dengan penelitian Cintya Andriani dkk (2013) Hasil analisis univariat menunjukkan nilai rerata IMT sebelum hamil pada pasien preeklampsia berada pada kategori normal, dengan nilai rerata IMT 22,3 Kg/m2. Juga Dumais, C. dkk (2016) yang menyimpulkan terdapat hubungan antara obesitas pada kehamilan dengan preeklampsia pada wanita hamil di RSUP Prof.Dr.R.D.Kandou Manado. Keadaan fisik lingkungan yang tidak sehat yang menimbulkan penyakit pada masyarakat di suatu wilayah. Penggunaan halaman untuk tanaman yang bermanfaat, seperti untuk menanam sayuran dan buah-buahan, dapat menyediakan makanan yang bergizi. Kondisis geografi juga memengaruhi kesehatan ibu dan anak balita (Vasra, 2013). Kejadian preklamsia dapat dipengaruhi lingkungan yang merupakan tempat beradaptasi dan gaya hidup yang berbeda. Berawal peningkatan tekanan darah yang berdampak pada preeklamsia/eklamsia bahkan kematian pada ibu hamil.

Dari beberapa factor yang mempengaruhi kejadian pre eklasmi maka factor yang paling dominan adalah umur ibu hamil. dengan nilai (B : 1.689, Exp B 5.414). Rentang umur kategori tidak beresiko (20-35) tahun sebanyak 20 orang (9,9\%), dan kejadian preeclampsia dengan umur beresiko $(<20$ dan $>35)$ tahun sebanyak 53 orang $(41,1 \%)$. Sehingga dengan bertambahnya usia ibu hamil dapat memungkinkan terjadinya preeclampsia.

\section{KESIMPULAN DAN SARAN}

Ditemukan $73(21,9 \%)$ ibu hamil yang mengalami preeklamsia dari 332 ibu hamil, terdapat perbedaan proporsi secara bermakna antara umur dengan kejadian pre eklamsia, indeks massa tubuh (IMT) mempengaruhi kejadian pre eklamsia, terdapat perbedaan proporsi secara bermakna atau dengan kata lain paritas mempengaruhi kejadian pre eklamsia serta lingkungan pemukiman ibu hamil mempengaruhi kejadian pre eklamsia. Hasil penelitian Menjadi bahan masukan dan rekomendasi bagi Pemerintah Kabupaten Bulukumba dalam membuat kebijakan yang lebih terarah dan berfokus pada penanggulangan preeklamsia pada ibu hamil dan menjadi sumber data untuk peneliti selanjutnya. 


\section{ACKNOWLEDGEMENTS}

Terima kasih kepada Stikes Panrita Husada Bulukumba atas hibah penelitian yang diberikan kepada penelitian dan kepada mahasiswa kebidanan yang membantu dalam pengambilan data di puskesmas sekabupaten Bulukumba.

\section{DAFTAR PUSTAKA}

Anita Safitri, Penulis and Halijah, (2017) HUBUNGAN GRAVIDITAS DENGAN KEJADIAN PREEKLAMPSIA DI RUMAH SAKIT UMUM DEWI SARTIKA KENDARI PROVINSI SULAWESI TENGGARA TAHUN 2016. Karya Tulis Ilmiah thesis, Poltekkes Kemenkes Kendari

Andriani, C., Lipoeto, N. I. and Indra Utama, B. (2016) 'Hubungan Indeks Massa Tubuh dengan Kejadian Preeklampsia di RSUP Dr. M. Djamil Padang', Jurnal Kesehatan Andalas, 5(1), pp. 173-178. doi: 10.25077/jka.v5i1.464.

Darma, K. K. (2011). Metode penelitian keperawatan pedoman melaksanakan dan menerapkan hasil penelitian . Jakarta Timur : CV Trans info Media .

Departemen Kementerian Kesehatan Republik Indonesia Tahun 2016

Dinas Kesehatan Kabupaten Bulukumba Tahun 2014

Dumais, C. ., Lengkong, R. A. and Mewengkang, M. E. (2016) 'Hubungan obesitas pada kehamilan dengan preeklampsia', e-CliniC, 4(1). doi: 10.35790/ecl.4.1.2016.11686.

Risnawati, R. and Kurniati, E. (2018) 'Hubungan Graviditas dengan Kejadian Preeklamsia pada Ibu Bersalin Kabupaten Bulukumba Tahun 2017', Journal of Healthcare Technology and Medicine, 4(2), p. 218. doi: 10.33143/jhtm.v4i2.211.

Herawati, Evi and Nikmah, Laily (2017) HUBUNGAN USIA DENGAN KEJADIAN PREEKLAMPSIA PADA IBU BERSALIN DI RSUD MUNTILAN. Skripsi thesis, Universitas 'Aisyiyah Yogyakarta

Nurjasmi et al. (2016). Buku Acuan Midwifery Update 2016. Jakarta: Pengurus Pusat IBI.

Sugiyono. (2012). Metode penelitian kuantitatif kualitatif dan $R \& D$. Bandung: Alfabeta.

Sulistyawati, A. (2013). Asuhan Kebidanan Pada Masa Kehamilan. Jakarta: Salemba Medika.

Syamsuddin et al. (2015). pedoman praktis metode penelitian internal. ponorogo: cv wade group.

Rachmat latief, SpPD-KPTI., M.Kes., FINASIM et al. (2015). Profil kesehatan Provinsi sulawesi selatan. Makassar: Dinas kesehatan provinsi sulawesi selatan.

Sumami, S., Hidayat, S. and Mulyadi, E. (2014) 'Hubungan gravida ibu dengan kejadian preeklampsia', EJournal Keperawatan, 4, pp. 3-7.

Vasra, E. (2014). Asuhan Kebidanan Komunitas Konsep Dan Praktik. jakarta: EGC. 